\title{
Fenestrated azygos A2 segment: a rare anatomic variation
}

\author{
Abdolkarim Rahmanian ${ }^{1}$ and Nima Derakhshan ${ }^{2^{*}}$ (D)
}

\begin{abstract}
Advancement in neurovascular imaging has led to detection of abnormalities and normal anatomic variations. Most of anatomical variations in cerebral vasculature are asymptomatic and found incidentally; however, some may increase the risk of aneurysm formation and subsequent subarachnoid or intracranial hemorrhage. Here in, we report fenestration within an azygos A2 segment, as an incidental finding, which is an extremely rare anatomic variation in a patient suffering subarachnoid hemorrhage (SAH). However, there was no correlation found between $\mathrm{SAH}$ and the mentioned anatomic variation. To author's knowledge this is the first report of such anatomic variation with providing source images of brain $\mathrm{CT}$ angiograms.
\end{abstract}

\section{Background}

The anterior cerebral arteries are devided into five segments:

- A1: from internal carotid artery (ICA) to the anterior communicating artery (A-comA).

- A2: from the A-comA to the region between genu and rostrum of corpus callosum where it bifurcates.

- A3: Bifurcation of A2 segment to pericallosal and callosomarginal which curves around the genu of corpus callosum and ends at the rostral part of body of corpus callosum.

- A4 and A5: distal branches on the superior surface of corpus callosum with anastomoses to distal branches of MCA and PCA.

Fenestration of intracranial arteries was found on 0.3 to $0.9 \%$ of cerebral angiograms, which is more common in posterior circulation and was claimed to be associated with saccular aneurysms. Although fenestration in anterior circulation is rare, azygos (unpaired) anterior cerebral artery (ACA) has been described in the literature as an anatomical variant.

Here in we report the first case of fenestration within of an azygos A2 segment of ACA which is an extremely

\footnotetext{
*Correspondence: nima_med83@yahoo.com

${ }^{2}$ Shiraz Neuroscience Research Center, Department of Neurosurgery, Shiraz University of Medical Sciences, Shiraz, Iran

Full list of author information is available at the end of the article
}

rare anatomical variation detected in brain computed tomography angiography (CTA).

\section{Case presentation}

A 22-year-old female suffered suddenly onset severe headache. She had Glasgow coma scale (GCS) of 15/15 and her neurologic exam was unremarkable. She was found to have subarachnoid hemorrhage (SAH) within left sylvian fissure on her brain computed tomography (CT) scan (Fig. 1). So a brain CT angiography with a 16slice multidetector scan was requested for her, which did not reveal any vascular lesion justifying SAH within left sylvian fissure. However we incidentally noticed a fenestrated azygos A2 segment in coronal images of maximum intensity projections (MIP) of her CTA (Fig. 2a, 2b). For determination of SAH source, she underwent a digital subtracted angiography (DSA) of brain 2 weeks later, which also did not show any aneurysms. Written consent was obtained from the patient to present this report and any images accordingly.

\section{Discussion}

Fenestration of arteries, described as division of arterial lumen into separate channels, each having a unique endothelial and muscularis layer, is commonly seen in cerebral arteries [1,2]. Angiographic incidence of arterial fenestration is 0.3 to $0.9 \%$, and they were thought to be more common in posterior circulation [1-3]. However two studies conducted by Van Rooij et al. [4, 5] demonstrated that fenestrations are more common in anterior 


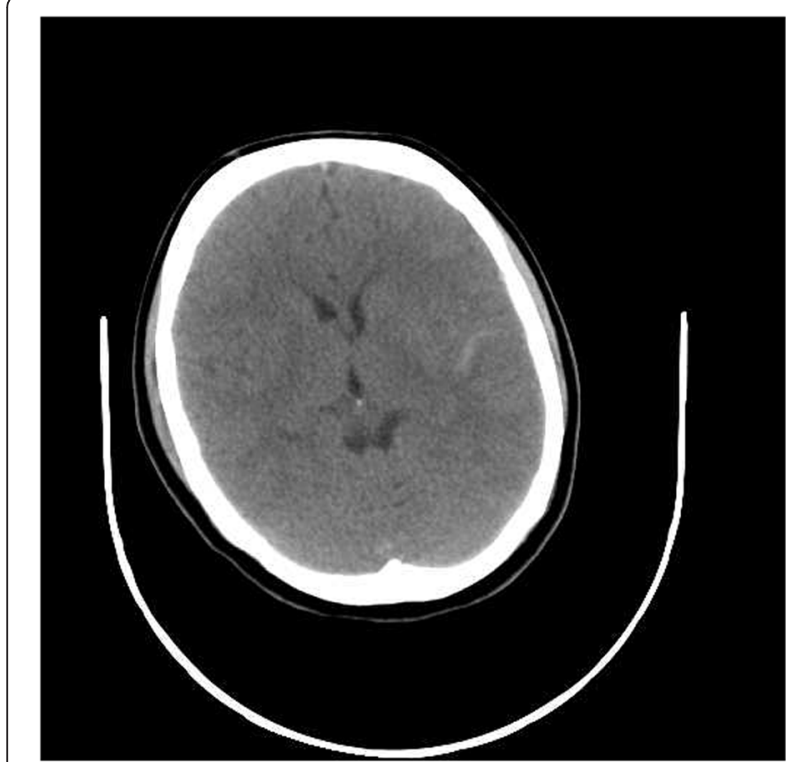

Fig. 1 Axial non-contrasted brain CT scan showing a streak of left parietal SAH

circulation by using the more sensitive diagnostic modality, namely three-dimensional rotational angiography (3DRA). They also found out that $31 \%$ of arterial fenestrations are associated with an aneurysm.

Despite several reviews about fenestrations in posterior circulation, the literature lacks sufficient data regarding fenestrations in anterior circulation.

Uchino et al. were the pioneers of reviewing anomalies in anterior circulation by investigation 2000 brain MR angiograms. They found an incidence of $0.3 \%$ for fenestrations in Middle cerebral artery (MCA) territory, which were all located in M1 segment [6].

Anomalies of Anterior cerebral artery including unilateral A1 aplasia, triple A2, unpaired or azygos A2 and fenestrations are also uncommon. Unpaired (azygos) A2 segment have been recorded in about $2 \%$ and arterial fenestration in about $1.2 \%$ of MR angiograms [7]. Although aneurysms have been reported to accompany unilateral A1 aplasia, triple A2 and azygos A2, no association was found between fenestrations and aneurysms.

Most fenestrations in the territory of anterior cerebral artery are within A1 segment. Data reported from cohort series of Zhao et al. reviewing cranial MR angiograms, revealed quite the same incidence of $0.8 \%$ for fenestrations in ACA territory and all were detected in A1 segment [8].

Uchino et al. reported the first case of fenestration in A2 segment detected in magnetic resonance angiography which is the only available report of fenestration in A2 segment, which was also recorded in an azygos A2 such as our case [7].

Whether or not this anatomic variation is related with aneurysm formation or SAH is unclear. However

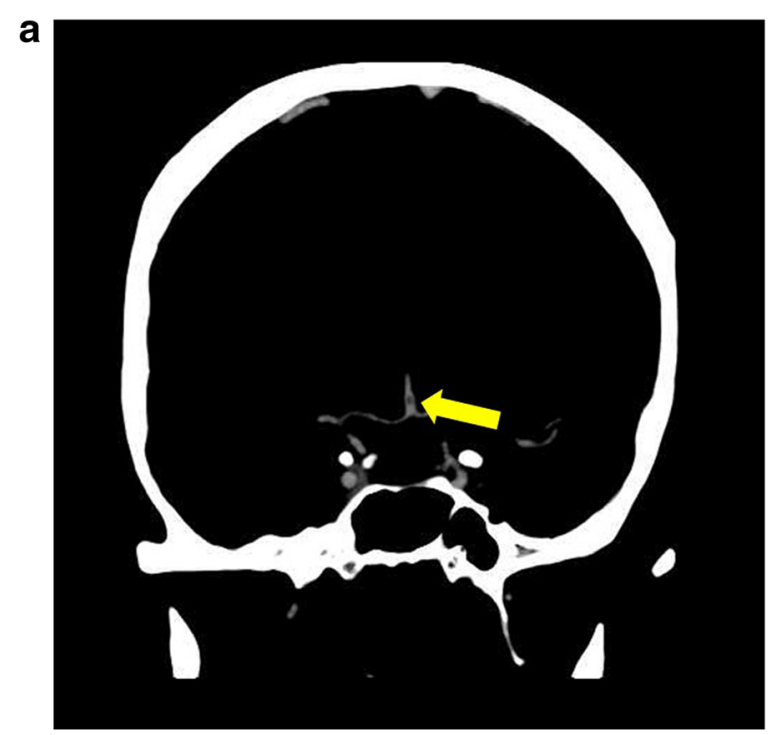

b

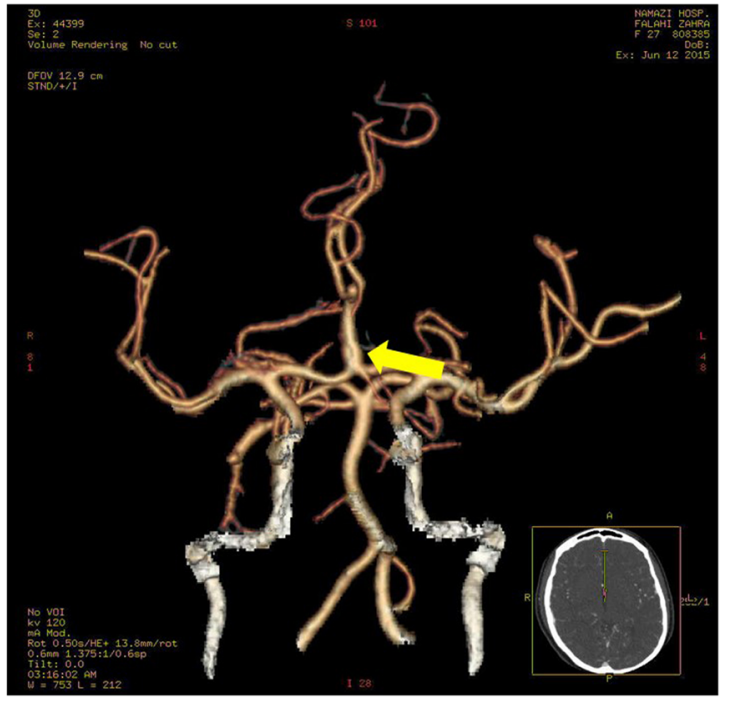

Fig. 2 a Coronal view of MIP images of brain CTA showing a fenestration at proximal part of an azygos A2 (Arrow). b 3DReconstruction of brain CTA from a coronal view highlighting the site of fenestration within an azygos A2 (Arrow)

to authors' knowledge this is an exteremely rare report of such an anatomic variation and might be considered among the various normal variations of cerebral arterial anatomy. Unlike previous report of detection of a similar anatomic variation by MRA, we spotted a fenestration in an Azygos A2 segment in brain CTA. Brain CTA is a valuable adjunct in neurovascular imaging and it can be used for assessment of vessels of small caliber.

\section{Conclusion}

Advancement in neurovascular imaging modalities has led to a better understanding of cerebrovascular anatomy. Unlike previous report of detection of a similar anatomic variation by MRA, we spotted a fenestration in an Azygos 
A2 segment in brain CTA. Brain CTA is a valuable adjunct in neurovascular imaging and it can be used for assessment of vessels of small caliber.

\section{Competing interests}

The authors declare that they have no competing interests.

\section{Authors' contributions}

AR noted this anomaly and its significance in the literature and revised the manuscript for final submission. ND did the literature review and provided the manuscript files and figures and obtained informed consent from the patient. All authors read and approved the final manuscript.

\section{Author details}

'Department of Neurosurgery, Shiraz University of Medical Sciences, Shiraz, Iran. ${ }^{2}$ Shiraz Neuroscience Research Center, Department of Neurosurgery,

Shiraz University of Medical Sciences, Shiraz, Iran.

Received: 2 July 2015 Accepted: 15 October 2015

Published online: 15 December 2015

\section{References}

1. Dimmick SJ, Faulder KC. Fenestrated Anterior Cerebral Artery with Associated Arterial Anomalies: Case Reports and Literature Review. Interv Neuroradiol. 2008;14(4):441-5.

2. Ihara S, Uemura K, Tsukada A, Yanaka K, Nose T. Aneurysm and fenestration of the azygos anterior cerebral artery-case report. Neurol Med Chir (Tokyo). 2003:43(5):246-9.

3. Sanders WP, Sorek PA, Mehta BA. Fenestration of intracranial arteries with special attention to associated aneurysms and associated anomalies. Am J Neuroradiol. 1993;14:675-80.

4. van Rooij SB, Bechan RS, Peluso JP, Sluzewski M, van Rooij WJ. Fenestrations of Intracranial Arteries. AJNR Am J Neuroradiol. 2015:36(6):1167-70.

5. van Rooij SB, van Rooij WJ, Sluzewski M, Sprengers ME. Fenestrations of intracranial arteries detected with 3D rotational angiography. AJNR Am J Neuroradiol. 2009;30(7):1347-50.

6. Uchino A, Nomiyama K, Takase Y, Egashira R, Kudo S. Fenestration of the middle cerebral artery detected by MR angiography. Magn Reson Med Sci. 2006;5(1):51-5.

7. Uchino A, Nomiyama K, Takase Y, Kudo S. Anterior cerebral artery variations detected by MR angiography. Neuroradiology. 2006;48:647-52.

8. Zhao HW, Fu J, Lu ZL, Lü HJ. Fenestration of the anterior cerebral artery detected by magnetic resonance angiography. Chin Med J (Engl). 2009:122(10):1139-42.

\section{Submit your next manuscript to BioMed Central and take full advantage of:}

- Convenient online submission

- Thorough peer review

- No space constraints or color figure charges

- Immediate publication on acceptance

- Inclusion in PubMed, CAS, Scopus and Google Scholar

- Research which is freely available for redistribution 